\title{
Análise Físico-Química e Biológica da Agua do Lago do Jardim Botânico de Goiânia (GO)
}

Carlos Eduardo R. Sant'Ana, Georgia R. S. Sant'Ana \& Luiz C. P. da Silva

O presente trabalho objetivou analisar fatores físico-químicos e biológicos da água do lago do Jardim Botânico de Goiânia e compará-los com os valores preconizados pela Resolução nº 357/2005 do Conselho Nacional do Meio Ambiente - CONAMA. As amostras de água foram coletadas mensalmente, nas estações seca e chuvosa, de junho de 2004 a julho de 2005. A análise dos dados sugere a presença de impactos ambientais, como descarga de esgotos clandestinos e infiltrações da rede de esgoto domésticos, o que indica a necessidade de políticas ambientais voltadas para conservação e manejo desses ecossistemas aquáticos e de seu entorno.

Palavras-chaves: Parâmetros físico-químicos, análise da água, ambientes aquáticos.

Physicochemical and biological analyses were carried out on water samples collected monthly for the period of one year from June 2004 to July 2005, from a lake in the Botanical Garden of Goiânia. The results obtained were compared with CONAMA standards (Resolution No. 357/2005) and indicated the presence of environmental impacts such as clandestine disposal of sewage and infiltration of domestic sewage. Educational programs and environmental policies for conservation and management of these aquatic environments must be organized by researchers and government agencies.

Keywords: Physico-Chemical parameters, water analyses, aquatic environments. 


\section{Introdução}

A água é essencial para existência e bem-estar do ser humano, devendo ser disponível em quantidade suficiente e boa qualidade, para garantir qualidade de vida, ${ }^{1,2}$ além de ser um recurso que influencia a economia de diversos países $^{3,4,5,6}$. O ambiente hídrico e toda a estrutura biótica e abiótica que o compõem têm sofrido elevadas pressões antrópicas nas últimas décadas e diversas técnicas de agricultura utilizadas têm provocado grande degradação ambiental ${ }^{7,8,9}$. Também são inúmeras as impurezas que se apresentam nas águas naturais, algumas inócuas e outras extremamente perigosas ${ }^{10,11,12}$.

Desde 1950, o Brasil apresenta problemas de escassez hídrica que decorrem principalmente do crescimento populacional e industrial, exclusão social e a expansão agrícola ${ }^{9,13,14}$, sendo os efluentes domésticos os grandes responsáveis pela degradação dos recursos hídricos ${ }^{15}$.

O Brasil possui uma grande oferta de água doce superficial, detém $11,5 \%$ da água doce superficial mundial e $34,9 \%$ do continente americano e é o $25^{\circ}$ país com maior oferta per capta ${ }^{16}$. Apesar de o Brasil ser um dos países de maior disponibilidade hídrica, porém, por conta de suas dimensões geográficas e condições climáticas diferenciadas ${ }^{17}$, a gestão dos recursos hídricos tem merecido, nos últimos anos, ampla discussão em razão da degradação qualitativa e quantitativa desses recursos ${ }^{18}$, que incluem as consequências de eventuais mudanças climáticas ${ }^{19}$.

A análise da água de um manancial pode evidenciar o uso inadequado do solo, os efeitos do lançamento de efluentes, suas limitações de uso e seu potencial de autodepuração ${ }^{20}$, isto é, sua capacidade de restabelecer o equilíbrio após recebimento de efluentes. Dentre os parâmetros utilizados para qualificar a água, estão os físico-químicos $(\mathrm{pH}$, cloretos, alcalinidade, nitratos, fosfatos, turbidez, condutividade), os biológicos (clorofila- $\alpha$ ) e microbiológicos (coliformes fecais e totais) ${ }^{14,21,22}$.

O presente trabalho teve como objetivo analisar fatores físico-químicos e biológico da água do lago do Jardim Botânico, localizado em Goiânia, Goiás, que se encontra em meio urbano sob interferência de atividades urbanas, a fim de compará-los com os valores de referência preconizados pela Resolução no 357/2005 do Conselho Nacional do Meio Ambiente - CONAMA ${ }^{11}$.

\section{Metodologia}

O trabalho foi conduzido no lago do Jardim Botânico de Goiânia, Goiás. A área foi contemplada no projeto original de urbanização de Goiânia, elaborado pelo arquiteto Atílio Correia Lima. A partir da Lei Municipal 7.800, de 5 de março de 1998, a área passou a ter como finalidade "desenvolver pesquisa, divulgação, conservação, preservação e recuperação, além de programas de atividades de recreação e educação ambiental em logradouro"²3.

O Jardim Botânico está localizado na região sul de Goiânia (Figura 1). Limita-se ao sul com a Vila Santo Antônio (latitude 16 graus e 41 minutos sul), a noroeste com o Setor Pedro Ludovico (longitude 49 graus e 17 minutos oeste) e a leste com a Vila Redenção. Possui a forma de cauda de um peixe, com uma densa cobertura vegetal que apresenta diversos espécimes centenários de grande porte (coordenadas geográficas 0686358E e $8150179 \mathrm{~N}$ e altitude de aproximadamente 815 metros). Destinava-se a preservar uma área de mata primitiva de cerca de $1.000 .000 \mathrm{~m}^{2}$, remanescente do início de Goiânia. Na década de 1960, sob a administração do Estado, a $3^{\mathrm{a}}$ Radial, avenida que liga Goiânia ao município de Aparecida de Goiânia, cortou o Jardim Botânico ao meio, o que provocou a perda de aproximadamente $9.000 \mathrm{~m}^{2}$. $\mathrm{Na}$ atualidade, o Jardim Botânico de Goiânia apresenta uma área total de $990.992 \mathrm{~m}^{2}$, dividido em duas áreas: Área I, com 441.600 m2 e Área II, com $558.400 \mathrm{~m}^{2}{ }^{24}$

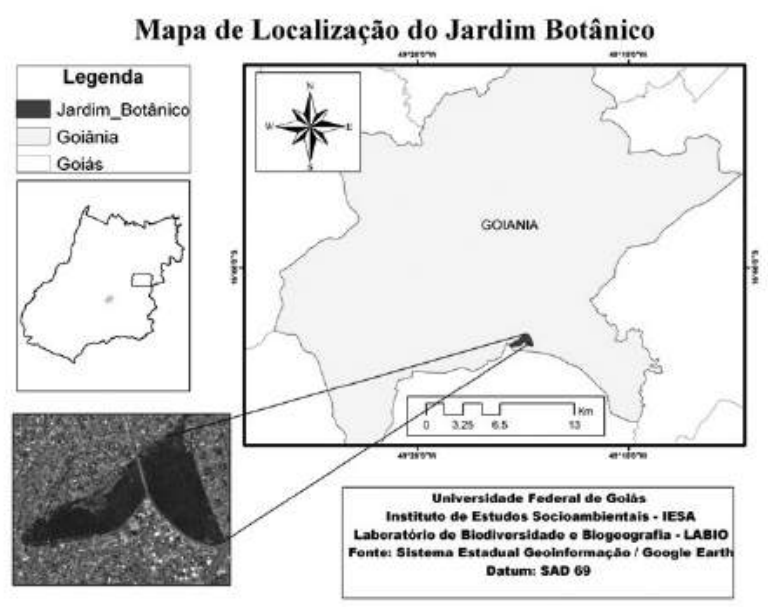

Figura 1. Mapa de localização do Jardim Botânico de Goiânia, Goiás. 
O principal curso d'água do Jardim Botânico é o Córrego Botafogo, a partir do qual se formam três lagos, e que possui três nascentes: duas localizadas na Área I e uma, na Área II. A nascente principal se encontra fora da área de preservação, submergida em áreas residenciais e canalizada. O escoamento do lago se dá por uma canalização sob a Avenida $1^{\text {a }}$ Radial, encontrando-se com as águas provenientes da nascente da Área II e seguindo por toda extensão do Jardim Botânico (aproximadamente $2.618,74 \mathrm{~m})$, recebendo outros afluentes, águas pluviais e esgotos clandestinos ao longo de todo o seu percurso, aproximadamente 15 quilômetros de extensão, seguindo até o seu encontro com o Rio Meia Ponte ${ }^{24,25}$.

Os dados referentes à pluviosidade mensal foram fornecidos pela equipe de Furnas (não publicados) e dados referentes à temperatura do ar e da água foram coletadas juntamente com as amostras de água nas datas de coleta. As amostras de água, por sua vez, foram coletadas mensalmente abrangendo parte das estações de seca e chuvosa, durante o período compreendido entre junho de 2004 a julho de 2005, exceto no mês de setembro de 2004 que, por problemas técnicos, não foi realizada a coleta. Os critérios para determinação dos pontos das coletas levam em consideração a facilidade de acesso, a representatividade dos pontos de amostragem em relação ao lago, a localização em área de grande urbanização, grande importância para a comunidade, dentre outros.
Foram analisados 12 parâmetros físico-químicos e um parâmetro biológico para o ambiente aquático em questão. As amostras de água foram coletadas subsuperficialmente, na margem dos lagos (região ecótica lêntica), sendo acondicionadas em caixa com gelo, levadas ao laboratório ao menor tempo possível14.21,22. Todas as coletas seguiram a norma NBR 9898/87 da $\mathrm{ABNT}^{26}$, no que se refere à preservação, técnicas de amostragem, efluentes líquidos e corpos receptores e NBR 10679/88 da $\mathrm{ABNT}^{27}$ de coleta, preservação e estocagem de amostras de águas minerais e de mesa. Alguns parâmetros, tais como $\mathrm{pH}$, condutividade, oxigênio dissolvido, turbidez e temperatura da água, foram determinadas em campo, com o auxílio de uma sonda multiparâmetro da marca YSI 6600. Os métodos de análise do laboratório baseiam-se no Standard Methods ${ }^{28}$, normas da ABNT26, ${ }^{27}$ e são descritos em manuais de qualidade ${ }^{21,22}$. Os dados geográficos foram coletados com GPS GARMIN modelo ${ }^{45}$.

\section{Resultados e Discussão}

$\mathrm{Na}$ Tabela 1, são apresentados os valores obtidos para as variáveis físico-químicas e biológica nos pontos de coleta no lago do Jardim Botânico, Goiânia-GO. O padrão sazonal das chuvas foi bem marcado. Durante o período das coletas, o período que mais choveu foi do mês de dezembro de 2004 (300 mm). A precipitação

Tabela 1. Valores dos parâmetros físico-químicos e biológico analisados no lago do Jardim Botânico de Goiânia, no período de junho de 2004 a julho de 2005.

\begin{tabular}{|c|c|c|c|c|c|c|c|c|c|c|c|c|c|c|c|c|c|c|c|}
\hline \multicolumn{20}{|c|}{ JARDIM BOTÂNICO } \\
\hline Variáveis & Unidade & $\begin{array}{l}\text { jun- } \\
04\end{array}$ & $\begin{array}{l}\text { jul- } \\
04\end{array}$ & $\begin{array}{l}\text { ago- } \\
04\end{array}$ & $\begin{array}{l}\text { out- } \\
04\end{array}$ & $\begin{array}{l}\text { nov- } \\
04\end{array}$ & $\begin{array}{l}\text { dez- } \\
04\end{array}$ & $\begin{array}{l}\text { jan- } \\
05\end{array}$ & $\begin{array}{c}\text { mar- } \\
05\end{array}$ & abr-05 & $\underset{05}{\operatorname{mai}-}$ & jun-05 & jul-05 & Média & Min & Máx & $\begin{array}{l}\text { Desvivo } \\
\text { Padria }\end{array}$ & $\mathrm{CV} \%$ & CONAMA \\
\hline Alcalinidade & $\begin{array}{l}\mathrm{m} / \ell / \ell \\
\mathrm{CaCO} 3\end{array}$ & 23,72 & 27,55 & 30,70 & 35,06 & 37,15 & 34,59 & 31,50 & 25,59 & 26,09 & 28,95 & 33,83 & 29,50 & 30,35 & 23,72 & 37,15 & 4,21 & 13,88 & * \\
\hline $\mathrm{pH}$ & & 6,0 & 6,60 & 6,70 & 5,72 & 6,60 & 6,50 & 6,20 & 7,09 & 6,20 & 6,50 & 7,00 & 6,20 & 6,44 & 5,72 & 7,09 & 0,40 & 6,19 & $6,0 \mathrm{a} 7,0$ \\
\hline Condutividade & $\mu \mathrm{S} / \mathrm{cm}$ & 117,0 & 110,0 & 147,0 & 191,0 & 250,0 & 241,0 & 127,0 & 218,00 & 114,00 & 126,00 & 125,00 & 125,00 & 157,58 & 110,00 & 250,00 & 52,44 & 33,28 & * \\
\hline Oxigênio Dissolvido & $\mathrm{mg} / \ell$ & 8,39 & 7,72 & 7,76 & 7,67 & 6,37 & 6,27 & 7,20 & 8,56 & 5,27 & 8,70 & 9,72 & 8,60 & 7,69 & 5,27 & 9,72 & 1,25 & 16,21 & $2,0 \mathrm{mg} / \mathrm{LO} 2$ \\
\hline Turbidez & NTU & 5,0 & 6,50 & 5,0 & 8,20 & 10,30 & 8,90 & 6,20 & 11,00 & 3,20 & 4,70 & 10,50 & 12,50 & 7,67 & 3,20 & 12,50 & 2,98 & 38,88 & $100 \mathrm{NTU}$ \\
\hline Nitrogênnio Total & $\mathrm{mg} / \ell$ & 3,08 & 2,80 & 2,49 & 1,01 & 0,73 & 0,92 & 2,02 & 2,03 & 3,30 & 3,30 & 2,86 & 2,18 & 2,23 & 0,73 & 3,30 & 0,92 & 41,38 & * \\
\hline Amônia & $\mathrm{mg} / \ell$ & 0,03 & 0,07 & 0,03 & 0,01 & 0,05 & 0,09 & 0,09 & 0,01 & 0,09 & 0,02 & 0,01 & 0,02 & 0,04 & 0,01 & 0,09 & 0,03 & 75,27 & Máx. $5,6 \mathrm{mg} / \mathrm{LN}$ para $\mathrm{pH} 7,5<\mathrm{pH} £ 8,0$ \\
\hline Nitrito & $\mathrm{mg} / \ell$ & 0,01 & 0,01 & 0,01 & 0,02 & 0,01 & 0,01 & 0,01 & 0,02 & 0,01 & 0,01 & 0,01 & 0,01 & 0,01 & 0,01 & 0,02 & 0,00 & 30,60 & $1,00 \mathrm{mg} / \mathrm{L} \mathrm{N}$ \\
\hline Nitrato & $\mathrm{mg} / \ell$ & 2,80 & 2,70 & 2,40 & 0,67 & 0,49 & 0,62 & 1,75 & 2,00 & 3,20 & 2,50 & 2,00 & 1,80 & 1,91 & 0,49 & 3,20 & 0.90 & 47,18 & $10,00 \mathrm{mg} / \mathrm{L} \mathrm{N}$ \\
\hline Fósforo Total & $\mathrm{mg} / \ell$ & 0,01 & 0,05 & 0,02 & 0,03 & 0,03 & 0,03 & 0,0 & 0,03 & 0,01 & 0,02 & 0,02 & 0,03 & 0,02 & 0,00 & 0,05 & 0,01 & 50,96 & $0,05 \mathrm{mg} / \mathrm{LP}$ \\
\hline Ortofosfato & $\mathrm{mg} / \ell$ & 0,0 & 0,0 & 0,0 & 0,0 & 0,0 & 0,0 & 0,0 & 0,00 & 0,00 & 0,00 & 0,00 & 0,00 & 0,00 & 0,00 & 0,00 & 0,00 & \#DIV//0! & * \\
\hline Clorofila & $\mu \mathrm{g} / \ell$ & 9,45 & 6,81 & 12,68 & 46,23 & 59,59 & 20,47 & 7,21 & 15,53 & 3,04 & 20,03 & 68,00 & 30,10 & 24,93 & 3,04 & 68,00 & 21,70 & 87,05 & Máx. 60,00 mg/L \\
\hline Cloretos & $\mathrm{mg} / \mathrm{Cll}-1$ & 11,39 & 11,57 & 10,93 & 10,17 & 8,32 & 8,23 & 6,81 & 7,14 & 7,97 & 10,51 & 11,47 & 10,51 & 9,59 & 6,81 & 11,57 & 1,77 & 18,43 & $250 \mathrm{mg} / \mathrm{LCl}$ \\
\hline Temperatura da Água & ${ }^{\circ} \mathrm{C}$ & 22,01 & 20,02 & 23,87 & 25,40 & 26,36 & 25,89 & 26,16 & 27,00 & 24,00 & 24,20 & 22,90 & 22,50 & 24,19 & 20,02 & 27,00 & 2,08 & 8,60 & $*$ \\
\hline Temperatura do Ar & ${ }^{\circ} \mathrm{C}$ & 22,0 & 20,0 & 27,0 & 22,80 & 21,0 & 24,0 & 25,0 & 24,00 & 27,45 & 28,00 & 25,00 & 24,00 & 24,19 & 20,00 & 28,00 & 2,50 & 10,35 & * \\
\hline
\end{tabular}


do mês de junho e agosto de 2004 foi 0,0 mm (Figura 2). A variação de temperatura do ar na área do lago do Jardim Botânico (Figura 3), nos meses de junho de 2004 a junho de 2005, apresentou um padrão sazonal cíclico com duas estações distintas: uma quente e úmida (abril, maio e agosto) e outra mais fria e seca (junho e julho), embora não tenha havido expressiva diferenciação entre os pontos de coleta ao longo dos meses.

De maneira geral, os períodos chuvosos podem ser considerados os de maior instabilidade para os corpos d'água tropicais. Isto é consequência das rápidas modificações que a chuva pode promover na água, que por sua ação como carreadoras de partículas e substâncias, sendo carreadas para os corpos d'água (material alóctone), pelos efeitos da diluição das chuvas mais intensas ${ }^{29}$. Desta forma, as chuvas atuam, tanto como fonte de aumento nas concentrações de partículas e certas substâncias na água, quanto como fonte de diluição dessas partículas. Os efeitos se diferenciarão principalmente pela época do ano, segundo a frequência e intensidade das precipitações ${ }^{30}$. A temperatura da água (Figura 4), no mês de março apresentou maior temperatura em média, ou seja, variando de $20,02^{\circ} \mathrm{C}$ e $27^{\circ} \mathrm{C}$.

A grande maioria dos corpos d'água continentais tem $\mathrm{pH}$ variando entre 6 e 8 . No entanto, podem-se encontrar ambientes mais ácidos ou mais alcalinos. Em ambos os casos, estes ecossistemas apresentam comunidades vegetais e animais característicos. Ecossistemas aquáticos que apresentam mais frequentemente valores baixos de pH têm elevadas concentrações de ácidos orgânicos dissolvidos de origem alóctone e autóctone ${ }^{29}$.

Os valores de $\mathrm{pH}$ observados na zona eufótica apresentaram-se frequentemente ácido ou próximo de neutro, que pode ser decorrente da intensa decomposição e respiração que resultam na produção de $\mathrm{CO}_{2}$ e diminuição do pH. Uma vez que o pH está relacionado ao equilíbrio das reações do ácido carbônico e das reações de carbonatos e bicarbonatos, todas relacionadas à concentração de $\mathrm{CO}_{2}$, os maiores valores encontrados na zona eufótica são uma consequência da intensa atividade fotossintética nesta região (consumo de $\mathrm{CO} 2$ ), como é o encontrado no mês de março e junho de 2005, em que os valores de $\mathrm{pH}$ estão entre o alcalino ou próxima de neutro. A menor média encontrada para os valores de pH 6,24 (Figura 5), foi encontrado em outubro de 2004, sendo esse $\mathrm{pH}$ classificado como fracamente ácido ou próximo de neutro, ver tabela $\mathrm{VI}^{31}$.

Acondutividade elétrica de uma soluçãoé a capacidade desta em conduzir corrente elétrica. Considerando-se que essa capacidade seja uma função da concentração dos íons presentes, é de se esperar que em soluções de maior concentração iônica, maior será a condutividade elétrica. Por outro lado, em águas muito puras, ocorre o fenômeno inverso: maior será a resistência e maior a condutividade $^{29}$. $\mathrm{O}$ pH também influencia a condutividade elétrica, que depende das concentrações iônicas e da temperatura e indica a quantidade de sais existentes no corpo d'água, e, portanto, representa uma medida indireta da concentração de poluentes ${ }^{32}$. O período de agosto de 2004 a dezembro de 2004 apresentou os valores mais altos de condutividade elétrica (Figura 6). Altos valores obtidos para a condutividade elétrica são característicos de ambientes impactados, em geral, níveis superiores a $100 \mu \mathrm{S} / \mathrm{cm}^{33}$

A alcalinidade, por sua vez, representa a capacidade que um sistema aquoso tem de neutralizar ácidos. Esta capacidade depende de alguns compostos, principalmente bicarbonatos, carbonatos e hidróxidos, sendo que este último ânion é raro na maioria das águas naturais, ocorrendo geralmente em águas cujo $\mathrm{pH}$ é superior a 10. A alcalinidade reflete, em última instância, a capacidade que um ecossistema aquático apresenta em neutralizar (tamponar) ácidos a eles adicionados ${ }^{29,33}$. De uma maneira em geral, todos os valores apresentaramse relativamente altos com relação à concentração da alcalinidade (Figura 7). Os maiores valores encontramse no mês de novembro de 2004 e junho de 2005 (entre $37,05 \mathrm{mg} / \ell \mathrm{CaCO} 3$ e $33,83 \mathrm{mg} / \ell \mathrm{CaCO} 3)$.

Dentre os nutrientes associados ao processo de eutrofização, destaca-se o fósforo, geralmente, escasso em ambientes aquáticos tropicais, o que faz com que os aportes provenientes de esgotos domésticos, ricos em fósforo tenham efeitos muito pronunciados. A quantificação do fósforo nos lagos alvo de estudo, foi realizada mediante duas análises ${ }^{28}$ : a) fósforo solúvel reativo (ortofosfato); b) fósforo total. O ortofosfato é a principal forma de fósforo assimilado pelos produtores primários no ambiente aquático. $\mathrm{O}$ fósforo total inclui todas as formas de fósforo presentes no sistema, orgânicos/inorgânicos e particulados/dissolvidos, e sua 


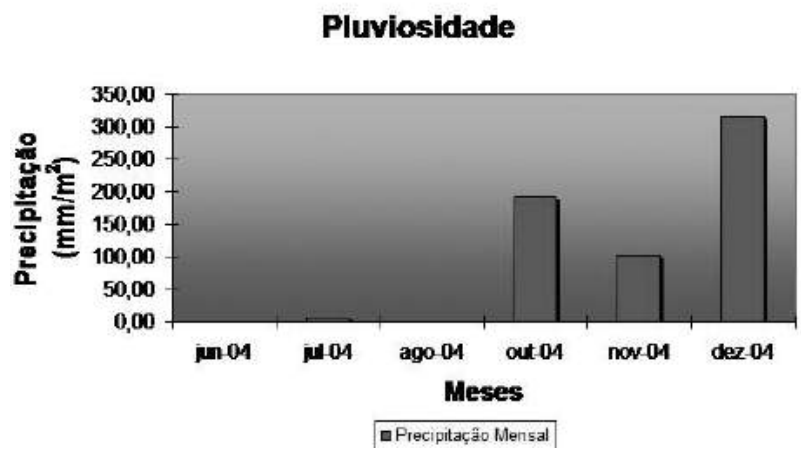

Figura 2. Valores de Precipitação total mensal entre junho de 2004 a dezembro de 2004 Fonte: Furnas - DCT.T.

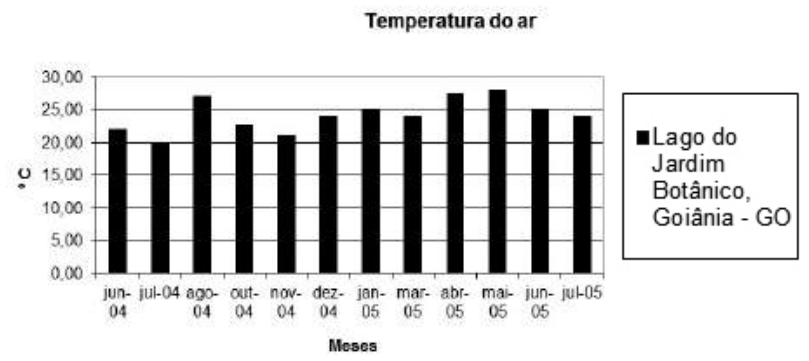

Figura 3. Variação da temperatura do ar, no lago do Jardim Botânico, Goiânia, Goiás, no período de junho de 2004 a julho de 2005.

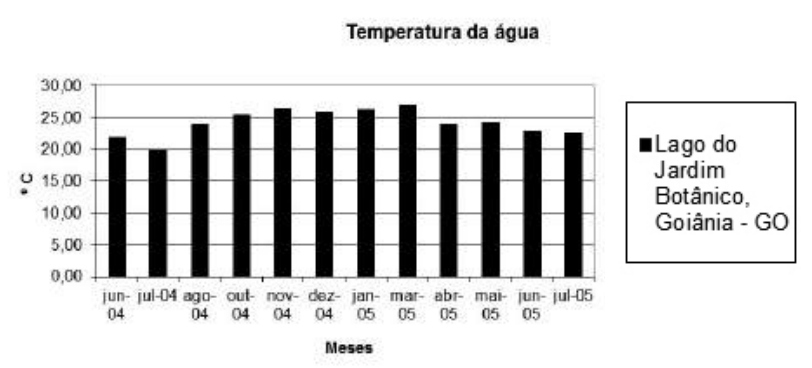

Figura 4. Variação da temperatura da água, no lago do Jardim Botânico, Goiânia, Goiás, no período de junho de 2004 a julho de 2005.

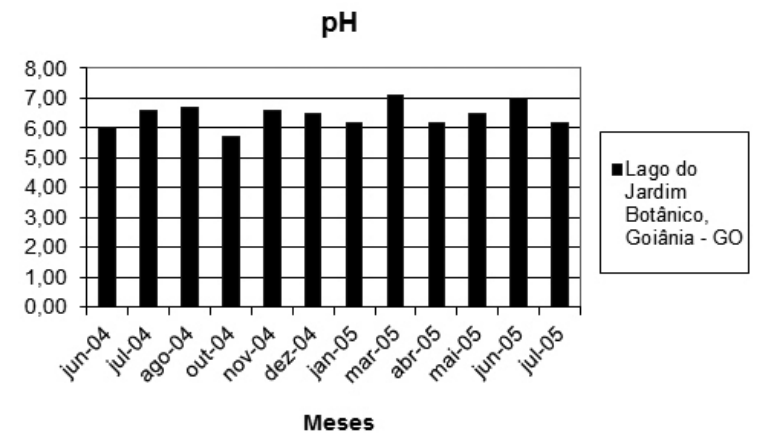

Figura 5. Variação do pH no lago do Jardim Botânico, Goiânia, Goiás, no período de junho de 2004 a julho de 2005.

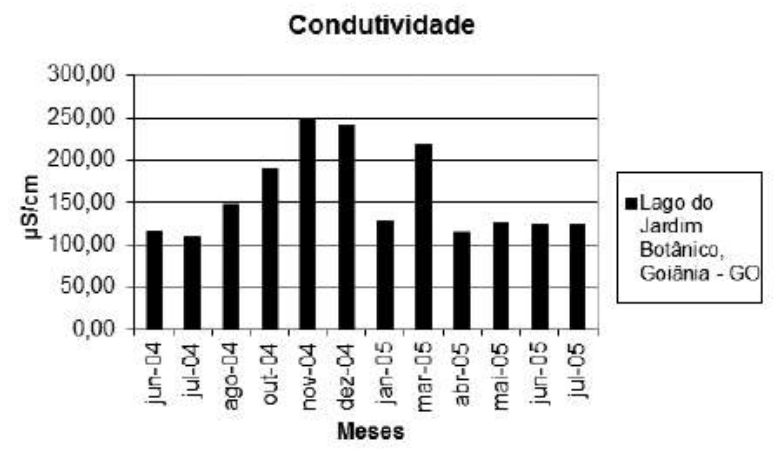

Figura 6. Variação de condutividade elétrica no lago do Jardim Botânico, Goiânia, Goiás, no período de junho de 2004 a julho de 2005.

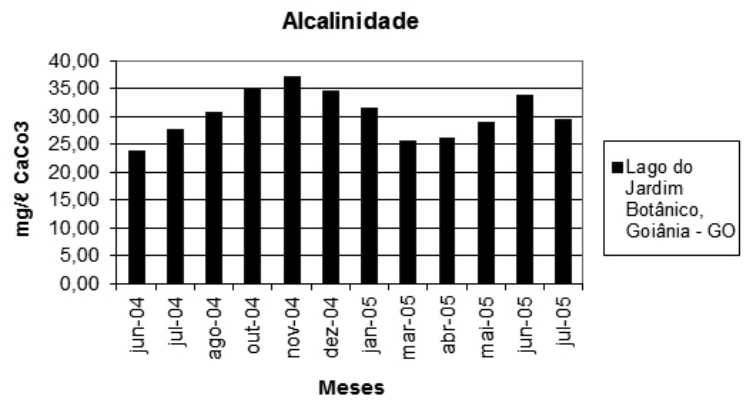

Figura 7. Variação de alcalinidade no lago do Jardim Botânico, Goiânia, Goiás, no período de junho de 2004 a julho de 2005. 
qualificação fornece dados importantes ${ }^{29}$. O fósforo total e o ortofosfato apresentaram-se em concentrações diferentes, ou seja, o ortofosfato não apresentou valores (Tabela 1) e o fósforo total apresentou maior concentração no período de junho de 2004. Os outros valores apresentaram concentrações de fósforo total abaixo deste período de junho de 2004. Em comparação com os valores de referência ${ }^{11}$, as concentrações de fósforo total não ultrapassaram o estipulado de $0,050 \mathrm{mg} / \mathrm{L}$ (Figura 8).

Outro aspecto a ser considerado é que o CONAMA ${ }^{11}$ estabelece limites que variam, de acordo com o pH dos corpos d'água. Como os lagos alvo do estudo, apresentaram valores de pH inferiores a 7,50, a Resolução prevê o valor máximo para a concentração de nitrogênio amoniacal de 13,30mg/L, em corpos d'água enquadrados na Classe 4 (águas destinadas à navegação, à harmonia paisagística). Ressalta-se que os valores encontrados para o período de junho de 2004 a julho de 2005 foram inferiores a esse valor (Figura 9).

$\mathrm{O}$ nitrito, por outro lado, corresponde à forma intermediária (e mais instável) dos íons nitrogenados. A conversão do nitrito em amônia ou nitrato é dependente das condições ambientais, como a disponibilidade de oxigênio. O nitrito é extremamente tóxico para grande parte da flora e da fauna aquática, mas algumas espécies fitoplanctônicas utilizam o nitrito como fonte de nitrogênio quando submetidas a baixas concentrações de nitrogênio amoniacal e nitrato ${ }^{29}$. Os maiores valores de nitrito foram em outubro de 2004 e março de 2005, período que coincide com a maior concentração de chuvas na região (Figura 10). Dentre as diferentes formas, o nitrato, juntamente com o íon amônio, assume grande importância nos ecossistemas aquáticos, uma vez que representam as principais fontes de nitrogênio para os produtores primários ${ }^{22}$. O nitrato apresentou concentrações muito superiores às demais formas inorgânicas de nitrogênio (Figura 11), sendo a principal forma de nitrogênio inorgânico nos lagos. Em alguns períodos, a concentração de nitrato apresentou grandes oscilações durante o período amostrado de $0,49 \mathrm{mg} / \ell$ a $3,20 \mathrm{mg} / \ell$ (entre novembro de 2004 a novembro de 2005). Quanto às concentrações de nitrato permitidas pelo CONAMA ${ }^{11}$, as concentrações apresentam-se com valores inferiores ao limite estabelecido para a Classe 4, que é de 10,0mg/L.
As análises biológicas são de grande importância na caracterização dos ambientes aquáticos. Isto é especialmente verdadeiro para os trópicos, em que o rápido metabolismo da comunidade fitoplanctônica pode promover a depleção nos níveis de nutrientes, dificultando a determinação do grau trófico do sistema. Em situações de grande densidade fitoplanctônica, que são típicas de sistemas eutrofizados, os níveis de nutrientes podem ser mantidos baixos pelo consumo fitoplanctônico, tornando fundamental a avaliação de variáveis biológicas para permitir uma melhor caracterização da água ${ }^{29}$. O estudo da composição pigmentar completa das populações vem revelando-se de grande importância ecológica e taxonômica. Os pigmentos podem ser rapidamente degradados durante períodos de carência de nutrientes, de estresses e na morte das células. Portanto, o conhecimento da presença e da concentração de vários pigmentos e de seus produtos de degradação é um valioso indicador do estado fisiológico das células fitoplanctônicas. Convém lembrar que ocorrem populações com composições pigmentares bastante diversas ${ }^{34}$. Em comparação com os valores estipulados pelo CONAMA ${ }^{11}$ (valores inferiores a $60,0 \mu \mathrm{g} / \mathrm{L}$ de clorofila- $\alpha$ para águas de Classe 4), o valor obtido para o mês de junho de 2005 ultrapassou a concentração estipulada, com $68 \mathrm{mg} / \ell$, já os outros valores mantiveram-se abaixo do estipulado pela legislação.

As concentrações de oxigênio dissolvido apresentaram valores acima do especificado pelo CONAMA11, tanto no período da seca, como no período da chuva. Isso evidencia que o ambiente vem sofrendo grande descarga de matéria orgânica (Figura 12). Dessa forma, os resíduos orgânicos despejados nos corpos d'água são decompostos por microrganismos que utilizam o oxigênio na respiração. Assim, quanto maior a carga de matéria orgânica, maior o número de microrganismos decompositores e, consequentemente, maior o consumo de oxigênio menor a concentração de oxigênio dissolvido no corpo d'água ${ }^{32,35}$.

Os principais responsáveis pela turbidez da água são principalmente as partículas suspensas (bactérias, fitoplâncton, detritos orgânicos e inorgânicos) e em menor escala, os compostos dissolvidos. Estes são responsáveis pela cor verdadeira da água e o material em suspensão pela cor aparente ${ }^{29}$. Os parâmetros 


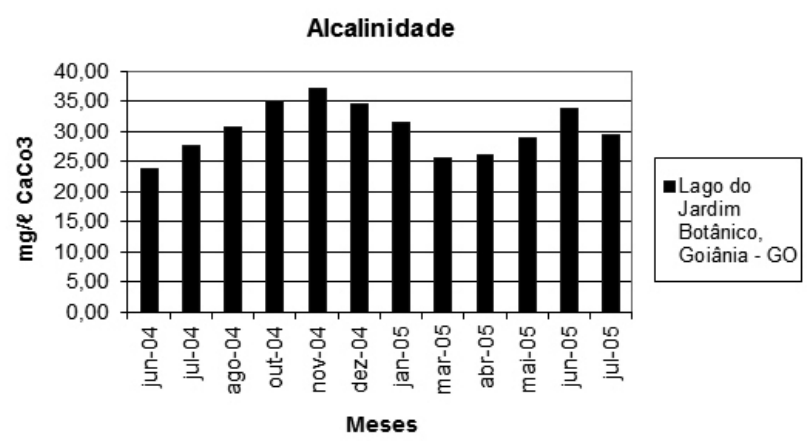

Figura 8. Variação do Fósforo Total no lago do Jardim Botânico, Goiânia, Goiás, no período de junho de 2004 a julho de 2005.

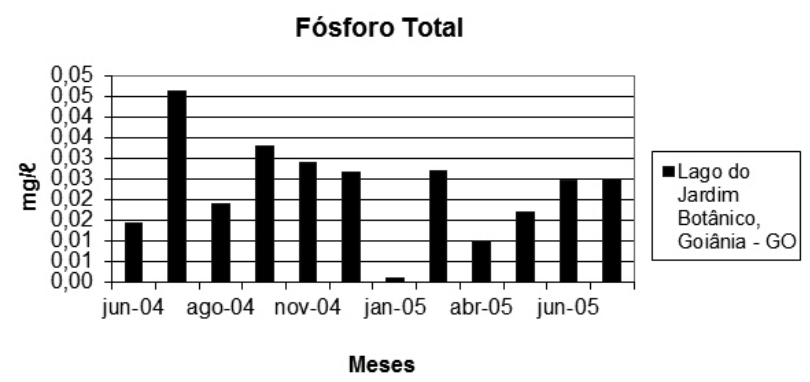

Figura 9. Variação do Íon Amônio no lago do Jardim Botânico, Goiânia, Goiás, no período de junho de 2004 a julho de 2005.

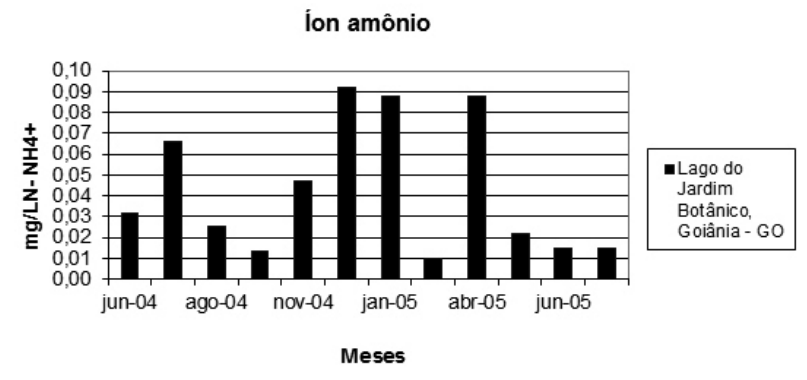

Figura 10. Variação do Nitrito no lago do Jardim Botânico, Goiânia, Goiás, no período de junho de 2004 a julho de 2005.

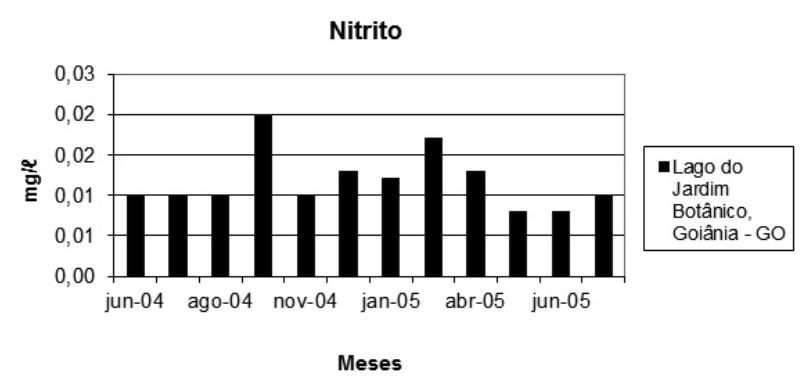

Figura 11. Variação do Nitrato no lago do Jardim Botânico, Goiânia, Goiás, no período de junho de 2004 a julho de 2005.

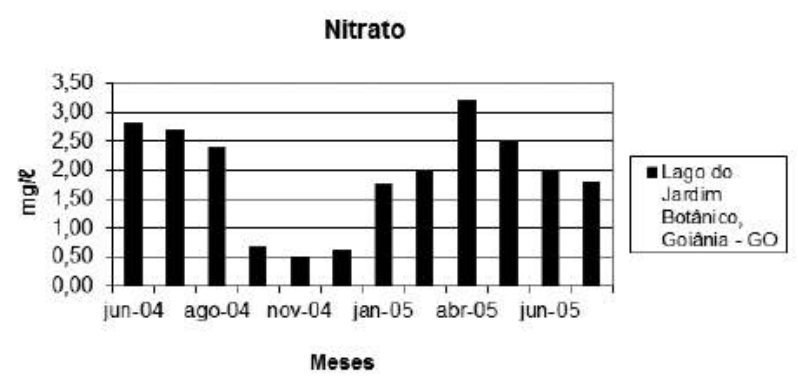

Figura 12. Variação do Oxigênio Dissolvido no lago do Jardim Botânico, Goiânia, Goiás, no período de junho de 2004 a julho de 2005.

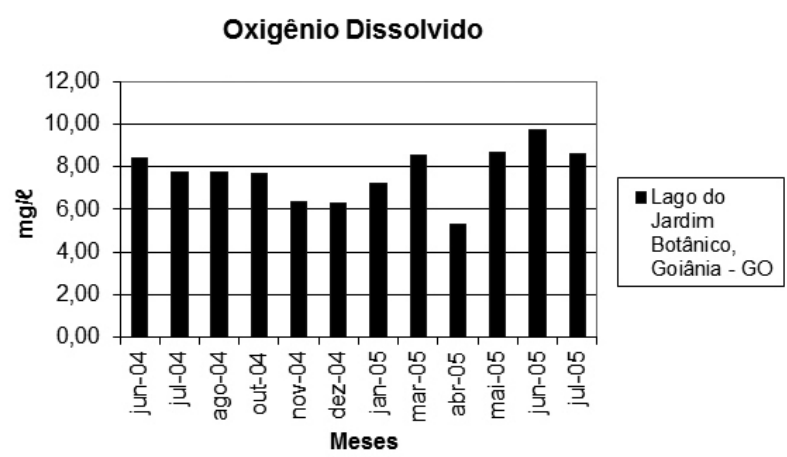

Figura 13. Variação de Turbidez no lago do Jardim Botânico, Goiânia, Goiás, no período de junho de 2004 a julho de 2005. 


\section{Artigo Geral 4}

climatológicos de uma região também influenciam os parâmetros avaliados, como a turbidez do corpo d'água. Em um período de maior precipitação, pode ocorrer aumento na turbidez, em função do grande aporte de material que é carreado pelas chuvas para o corpo d'água em questão ${ }^{20}$, como o que provavelmente ocorreu no período chuvoso, que apresentaram valores altos. De acordo com o CONAMA11, para os lagos de Classe 4 (águas destinadas à navegação e á harmonia paisagística) o valor de turbidez não pode ultrapassar 100 NTU's e todos os valores obtidos nas amostras do Jardim Botânico de Goiânia estão abaixo desse limite.

Outro indicador de poluição por esgotos domésticos nas águas naturais é o teor de cloretos, uma vez que excretas humanos contêm cerca de $6 \mathrm{~g}$ por pessoa ao $\mathrm{dia}^{32}$. Os maiores valores de cloretos encontrados foram em julho de 2004 e junho de 2005, mas nenhuma das amostras apresentou valores que ultrapassaram os valores de referência ${ }^{11}$ (Figura 14).

A análise dos dados indicou que esse corpo d'água recebe um considerável aporte de nutrientes, possivelmente através da descarga de esgotos clandestinos e infiltrações da rede de esgoto doméstico. Fato como esse já foi relatado pela equipe técnica da Prefeitura de Goiânia, que se deparou com uma fossa séptica em uma das nascentes do Córrego Botafogo, formador dos lagos do Jardim Botânico com o seu represamento ${ }^{24,25}$.

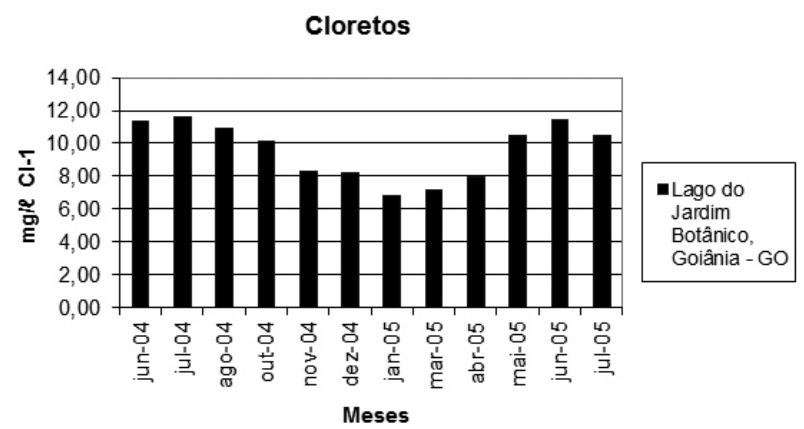

Figura 14. Variação de Cloretos no lago do Jardim Botânico, Goiânia, Goiás, no período de junho de 2004 a julho de 2005.

\section{Considerações Finais}

O presente trabalho avaliou as condições físicas, químicas e biológicas da água no lago do Jardim Botânico de Goiânia, Goiás, que se encontra em uma região urbana sob efeito de atividades antrópicas. Os resultados obtidos sugerem a existência de alterações ecológicas no lago estudado e fornecem subsídios para diagnósticos de impacto ambiental. Além disso, indicam a necessidade de políticas ambientais voltadas para conservação e o manejo desses ecossistemas aquáticos e de seu entorno, sobretudo, considerando a sua grande importância socioambiental e para a qualidade de vida da comunidade.

\section{Referências}

1. Freitas, V. P. S. et al. Rev. Inst. Adolfo Lutz, Campinas, 2002, 61(1), 51.

2. EPA - United States Environmental Protection Agency. The Importance of Water to the U.S. Economy: Synthesis Report. 2013. Disponível em: http://water.epa.gov. Acesso em 25/06/2014.

3. Bockstael, N. E.; Freeman, A. M.; Kopp III, R. J.; Portney, P. R.; Smith, V. K. Environmental Science and Technology, 2000, 34(8), 1384.

4. Shittu, O. B.; Olaitan, J. O.; Amusa, T. S. African Journal of Biomedical Research, 2008, 11, 285.

5. Manjare, S. A.; Vhanalakar, S. A.; Muley, D. V. International Journal of Advanced Biotechnology and Research, 2010, 1(2), 115 .

6. Ruddell, B. Embedded Resource Accounting: Evaluating the Comparative Intensity of Water Use in Multiple Sectors of the U.S. Economy, 2012.

7. Tundisi, J. G. Água no século XXI: enfrentando a escassez. RiMa: São Carlos, IIE, 2005.

8. Khan, S. A.; Ali, A.; Baig, M. N. Journal of Environmental Treatment Techniques, 2013, 1(1), 19.

9. Schock, N. T.; Murry, B. A.; Uzarski, D. G. Wetlands, 2014, 34(2), 297.

10. Barrel, R.; Benton, C.; Boyd, P.; Cartwright, R.; Chada, C.; Colbourne, J.; Cole, S.; Colley, A.; Drury, D.; Godfree, A.; Hunter, P.; Lee, J.; Machray, P.; Nicholis, G.; Sartory, D.; Sellwood, J; Watkins, J. The microbiology of drinking water-party water quality and public health. Methods for the examination of waters and associated materials. Environment Agency, 2002.

11. CONAMA - CONSELHO NACIONAL DO MEIO AMBIENTE. Resolução n. 357, de 17 de março de 2005. Brasília, 2005.

12. Moraes, D. S. de L.; Jordão, B. Q. Rev. Saúde Pública 2002, 36, 370. 
13. Carvalho, R. S. de. Água, um bem que precisa ser cuidado. 2004. Disponível em: <http://www.cnrh-srh.gov.br/artigos/main.htm>. Acesso em: 15 de outubro de $\mathbf{2 0 1 1}$.

14. Sant'Ana, G. R. S.; Sant'Ana, C. E. R.; Maciel, J. R.; Costa, C. R. Rev. Proc. Quím., 2009, 3(6), 48.

15. Baird, C; Cann, M. Environmental Chemistry. H. Freeman and Company: New York, 2012.

16. Grassi, M. T. As Águas do Planeta Terra. São Paulo: Caderno Temático de Química Nova na Escola, 2001.

17. Brito, L. T. de L. et al. Revista Brasileira de Engenharia Agrícola e Ambiental, Campina Grande, 2005, 9(4), 596.

18. Conte, M. L.; Leopoldo, P. R. Avaliação de recursos hídricos: Rio Pardo, um exemplo. Unesp: São Paulo, 2001.

19. Tao, F.; Yokozawa, M.; Hayashi, Y.; Lin, E. Ambio, 2003, 32(4), 295.

20. Grabow, W. Water S. A., Washington, 1996, 22(2), 193.

21. Golterman, H. L. Methods for chemical analysis of freshwater. Blacwell Scientific Publications: Oxford and Edinburgh, 1978.

22. Sperling, M. V. Introdução à qualidade das águas e ao tratamento de esgotos. Departamento de Engenharia Sanitária e Ambiental. UFMG: Belo Horizonte, 2005.

23. Amorin, M. A. P. et al. Caderno dos Parques do Município de Goiânia. SEMMA, 1997.

24. Sant'Ana, G. R. S. (org.). Plano de Manejo do Jardim Botânico Amália Hermano Teixeira, Goiânia, 2007.

25. SEMMA - SECRETARIA MUNICIPAL DO MEIO AMBIENTE. Relatório de Impacto Ambiental do Jardim Botânico, Goiânia, 1994.

26. ABNT. NBR 9897, 1987.

27. ABNT. NBR 10679, 1988.

28. Clesceri, L. S.; Geenberg, A. E.; Trussel, R. R. Standard Methods for the Examination of Water and Wastewater. Public Health Association, American Water Environments Federation, 20th Edition, 2005.
29. Esteves, F. de A. Fundamentos de Limnologia. 3.ed. Interciência: Rio de Janeiro, 2011

30. PLANCTON CONSULTORIA LTDA. Relatório de UHE Furnas 1996 a 2003. Belo Horizonte, 2003

31. EMGOPA - Empresa Goiana de pesquisa agropecuária. Universidade Federal de Goiás, Goiânia-GO, 1988

32. Richter, C. A.; Neto, J. M. A. Tratamento de água: tecnologia atualizada. Edgard Blucher: São Paulo, 1991.

33. Wetzel, R. G.; Linkens, G. E. Limnological Analyses. Springer: New York, 2010

34. Paranhos, R. Alguns Métodos Para Análise de Água. Rio de Janeiro: Cadernos didáticos UFRJ, 1996.

35. Baumgarten, M. G. Z.; Pozza, S. A. Qualidade de água: descrição de parâmetros químicos referidos na legislação ambiental. FURG: Rio Grande, 2001

\section{Carlos Eduardo R. Sant'Ana ${ }^{*}$, Georgia R. S. Sant'Ana ${ }^{2,3}$ \& Luiz C. P. da Silva ${ }^{4}$}

${ }^{1}$ Instituto de Estudos Socioambientais (IESA), Universidade Federal de Goiás, Campus Samambaia, Cx. Postal 131, 74001-970, Goiânia-GO, Brasil.

${ }^{2}$ Faculdade de Tecnologia SENAI Roberto Mange, 75113-630, Anápolis-GO, Brasil.

33ardim Botânico de Goiânia (AMMA), 74820-030, Goiânia-GO, Brasil.

${ }^{4}$ AQUALIT, Goiânia-GO, Brasil.

*E-Mail: cersantana@gmail.com 
